\title{
COOPERAÇÃO INTERNACIONAL: BOAS PRÁTICAS FISCAIS PARA ATINGIR JUSTIÇA GLOBAL
}

INTERNATIONAL COOPERATION: FISCAL GOOD PRACTICES TO ACHIEVE GLOBAL JUSTICE

MARIANA PASSOS BERALDO ${ }^{1}$

WAGNER MENEZES ${ }^{2}$

GERALDA CRISTINA DE FREITAS RAMALHEIRO ${ }^{3}$

\section{RESUMO}

Em 2019, apurou-se que 17\% de toda a riqueza global, detida por, no máximo, 0,1\% das pessoas no planeta é gerenciada por jurisdições de sigilo financeiro. Essa investigação buscou, após apresentar as limitações e as abrangências conceituais do conceito de justiça fiscal, identificar o mecanismo adequado para atingir a justiça fiscal, em patamar global. Isto porque é consenso que, em um momento de crescente desigualdade global de riqueza, o tax avoidance deve ser combatido, sendo esta uma luta que ultrapassa os limites territoriais dos Estados. Trata-se de uma pesquisa de natureza aplicada, que visa gerar conhecimento voltado à solução da problemática exposta, cujo problema foi abordado pela ótica qualitativa e com objetivo exploratório, viabilizado pelo estudo bibliográfico, cuja coleta de material focou na produção doutrinária internacional, escrita quase que na totalidade em língua inglesa e publicada, nos últimos 5 anos, amparado pelo método indutivo. 0 resultado apontou ser imprescindível a união das nações, adotando medidas de cooperação internacional, para atingir justiça fiscal, em patamar global. Ressaltou-se também a necessidade da ampliação de pesquisas sobre as percepções globais de justiça e a formulação de uma agenda, com a ampla participação pelos Estados, Organizações Internacionais e sociedade civil, para discutir a questão em debate.

PALAVRAS-CHAVE: Globalização. Planejamento fiscal agressivo. Concorrência fiscal prejudicial. Cooperação fiscal internacional. Justiça fiscal global.

1 Mestranda em Direito Internacional e Europeu na Faculdade de Direito da Universidade Nova de Lisboa - FDUNL e investigadora integrada no CEDIS - Centro de I\&D sobre Direito e Sociedade da mesma Faculdade. Pesquisadora colaboradora do Curso de Mestrado Profissional em Direito da Universidade de Araraquara - UNIARA. Professora assistente da Universidade de Araraquara - UNIARA e Tutora de Ensino à Distância na mesma Universidade. Advogada. ORCID Id: https://orcid. org/0000-0001-9268-9252. E-mail: mariana@pss.adv.br.

2 Mestre (PUCPR). Doutor (USP) (2007). Pós Doutor (Universitá Degli Studi di Padova - Itália) (2008). Livre-docente em Direito Internacional, USP, 2012. Professor Doutor na USP desde 2009. É professor Associado da Faculdade de Direito da Universidade de São Paulo - USP - no programa de graduação e pós-graduação em Direito. Consultor da Organização das Nações Unidas - ONU no Programa de combate a pirataria no mar, trafico de drogas e armas. ORCID iD: https://orcid.org/00000002-5850-9032. E-mail: wm@wagnermenezes.org.

3 Doutoranda em Desenvolvimento Regional e Meio Ambiente na Universidade de Araraquara - UNIARA. Mestre em Gestão de Organizações e Sistemas Públicos pela Universidade Federal de São Carlos - UFSCAR. Pesquisadora colaboradora dos Cursos de Mestrado Profissional em Direito e Mestrado em Desenvolvimento Territorial e Meio Ambiente da Universidade de Araraquara. Analista na Incubadora de Empresas de Araraquara. ORCID iD: https://orcid.org/0000-0002-6699-8235. E-mail: gee.cristina@gmail.com. 


\section{ABSTRACT}

In 2019 , it was found that $17 \%$ of all global wealth, held by a maximum of $0.1 \%$ of people on the planet is managed by financial secrecy jurisdictions. This investigation aimed, after presenting the limitations and conceptual scope of the concept of tax justice, to identify the appropriate mechanism to achieve tax justice, at a global level. The study is justified by the fact that there is a consensus that, in a moment of increasing global wealth inequality, tax avoidance must be combated, which is a struggle that goes beyond the territorial limits of the States. It is a research of an applied nature, which aims to generate knowledge aimed at the solution of the exposed problem, whose problem was approached from a qualitative perspective and with an exploratory objective, made possible by the bibliographic study, whose collection of material focused on the international doctrinal production, written almost that entirely in English and published in the last 5 years, supported by the inductive method. The result showed that the union of nations is essential, adopting international cooperation measures to achieve fiscal justice, on a global level. It also highlighted the need to expand research on global perceptions of justice and to formulate an agenda, with broad participation by States, International Organizations and civil society, to discuss the issue under debate.

Keywords: Globalization. Aggressive tax planning. Harmful tax competition. International tax cooperation. Global tax fairness.

\section{INTRODUÇÃO}

Os relatórios "Offshore Leaks", "Swissleaks", "Luxleaks" e "Panama Leaks" produzidos pela International Consortium of Investigative Journalists - ICIJ (2013; 2014; 2015; 2016) chegaram às manchetes a partir de 2013 , deflagrando vazamentos sobre offshore, paraísos fiscais e escândalos envolvendo sonegação e esquemas tributário agressivo, atividades tributárias até então pouco conhecidas (BARANGER, 2017; VAN HORZEN, 2017).

Segundo o The Boston Consulting Group, no mundo, aproximadamente 9,6 trilhões de dólares, que representou $17 \%$ de toda a riqueza global em 2019 , são gerenciados por jurisdições de sigilo financeiro, sendo a Suíça o principal destino, seguindo por Hong Kong e Cingapura. A empresa de consultoria destacou ainda que a pandemia do Covid-19 tende a levar a um aumento, a curto prazo, dos fluxos de capital transfronteiriços, devendo os investidores optar por movimentar seus ativos móveis para paraísos fiscais (ZAKRZEWSKI et al., 2020).

A maior parte da riqueza que é destinada para jurisdições com regimes tributários preferenciais e prejudiciais advém de uma rede opaca de empresas, fundos fiduciários e fundações, que pertencem, no máximo, a 0,1\% das pessoas no planeta. Muito desse investimento deriva de sonegação de impostos, cleptocracia, lavagem de dinheiro, suborno e outras atividades criminosas. Como resultado, contribuintes pessoas físicas e grandes corporações transnacionais não materializam a fair share e deixam de recolher tributos que financiariam o custeio e a prestação de serviços essenciais dos Estados, especialmente no caso dos países em desenvolvimento.

Destaca-se que em um momento de crescente desigualdade global de riqueza, tolerar a tax avoidance é simplesmente inaceitável (HENRY, 2016). Para reverter este quadro, cresce o entendimento de que a tributação progressiva sobre o rendimento da pessoa coletiva pode representar o principal instrumento de promoção da justiça em uma democracia liberal (GRINBERG, 2016). Contudo, o cumprimento da fair share e a promoção da justiça na esfera fiscal, precisam ir além da mera coordenação dos sistemas fiscais que propicia cooperação 
e troca de informações entre administrações tributárias, mas mantém lacunas e diferenças que possibilitam os comportamentos indesejáveis, tais como evasão e planejamento fiscal agressivo. Assim, em um mundo global, a justiça fiscal efetiva ultrapassa os parâmetros e limites do Estado, devendo ser pensada em termos globais e não mais na esfera doméstica dos Estados (DAGAN, 2017).

Diante do cenário exposto, o presente estudo busca responder a seguinte questão: como garantir justiça fiscal, em patamar global, diante da ausência de uniformidade das regras fiscais? O objetivo é discutir as limitações e as abrangências conceituais do termo justiça fiscal global frente ao mapeamento do desajustamento dos sistemas fiscais e identificar a ferramenta disponível mais adequada para atingir a justiça fiscal, em patamar global. A justificativa para o estudo proposto deve-se ao fato da concretização da justiça estar intimamente relacionada com a redução das desigualdades sociais e promoção da igualdade, que por sua vez, estão elencados como objetivos fundamentais da República Federativa do Brasil (BRASIL, 1988). Ademais, a cooperação entre as nações está entre os propósitos da Carta das Nações Unidas, promulgada pelo Decreto Federal nº 19.841, de 22 de outubro de 1945, disciplinados pelo artigo 1, que visa no item n. 3, "conseguir uma cooperação internacional para resolver os problemas internacionais de caráter econômico, social, cultural ou humanitário, e para promover e estimular o respeito aos direitos humanos e às liberdades fundamentais para todos, sem distinção de raça, sexo, língua ou religião" (BRASIL, 1945).

Para materializar tais objetivos, foi adotada a seguinte estratégia metodológica: pesquisa de natureza aplicada, pois visa gerar conhecimento voltado à solução da problemática exposta, cujo problema foi abordado pela ótica qualitativa e com objetivo exploratório, viabilizado pelo estudo bibliográfico, cuja coleta de material focou na produção doutrinária internacional, escrita quase que na totalidade em língua inglesa e publicada, nos últimos 5 anos, amparado pelo método indutivo. Em relação aos procedimentos metodológicos, adotou-se a revisão integrativa enquanto ferramenta analítica. A base de consulta escolhida foi Kluwer Law Online e as referências foram localizadas a partir das expressões: "global tax justice", "global tax fairness" e "internacional tax cooperation".

A partir da execução de tal estratégia, esse trabalho, dentro de um encadeamento lógico, foi organizado em quatro seções que se entrelaçam e se completam. Em termos práticos, ao longo do texto será constatado que a intensificação da cooperação dos Estados e a adoção de boas práticas fiscais se mostram como ferramentas adequadas para a promoção da justiça fiscal, em patamar global. Observa-se ainda a necessidade da ampliação de pesquisas sobre as percepções globais de justiça e a formulação de uma agenda, com a ampla participação pelos Estados, Organizações Internacionais e sociedade civil, para discutir a questão em debate. 


\section{O DESAJUSTAMENTO DOS SISTEMAS FISCAIS NACIONAIS FRENTE A REALIDADE ECONÔMICA GLOBAL COMO OBSTÁCULO PARA A CONCRETIZAÇÃO DA JUSTIÇA FISCAL}

Nas décadas mais recentes, os sistemas fiscais nacionais foram seriamente abaladas pelos efeitos nefastos da globalização no âmbito da fiscalidade (TANZI, 1999; 2000). Com a intensificação da concorrência fiscal, indivíduos e empresas passaram a ter mais liberdade na escolha de como e onde investir, minando assim, criticamente a capacidade dos Estados de promover a redistribuição doméstica da justiça, razão pela qual, a visão de justiça fiscal em patamar global cada vez mais se fortalece (DAGAN, 2017).

O mercado econômico global, marcado pela globalização da marca e operações, impactou na forma como as empresas multinacionais (EMNs) são estruturadas e gerenciadas. A competição global, a pressão crescente nos custos de produção, operação e necessidade do investimento em pesquisa e desenvolvimento (P\&D) resultam em uma pressão descendente nas margens e na lucratividade. Assim, as empresas precisam evoluir e se concentrar em maximizar as margens, inovando, melhorando a qualidade, concentrando-se em aumentar a eficiência operacional, reduzindo custos e gerenciando riscos. Mais do que nunca há necessidade de se traçar uma estratégia tributária adequada e eficaz, já que o elemento fiscal passa ser definidor na escolha de como e onde investir. Por consequência, a globalização tornou o planejamento tributário mais complexo e criando a necessidade de se alinhar a estratégia tributária com a realidade corporativa, estrutural e operacional (FINNERTY et al., 2007).

É consenso que no complexo ambiente de negócios de hoje, a estratégia tributária precisa ser global e tem como objetivo final alcançar e manter uma taxa de imposto efetiva mundial mais baixa. (FINNERTY et al., 2007) Contudo, todo esse movimento para obter melhor desempenho e superar a competitividade do mercado mundial, fez com que as EMNs se aproveitassem de esquemas e manobras empresariais, classificados como planejamentos fiscais agressivos, cuja a finalidade primeira e muitas vezes, única, seja reduzir ou eliminar a carga tributária decorrente de suas atividades (PASSOS; BERALDO, 2020).

Ainda no âmbito deste estudo, deve-se ser observado o impacto da globalização sob a ótica dos Estados. Referido fenômeno apresenta consequências contraditórias, pois o mesmo Estado que é, cada vez mais, dependente dos impostos para se financiar (finalidade fiscal), precisa também atuar de forma extrafiscal, com o objetivo de influenciar os comportamentos e/ou suprir as falhas de mercado, de justiça e de equidade (PIRES, 2018).

Nota-se que a mobilidade dos agentes econômicos, facilitada por elementos como comércio eletrônico, moeda digital, relações comerciais entre empresas do mesmo grupo, utilização de centros financeiros offshore e proliferação dos paraísos fiscais e regimes ficais prejudiciais, reflete profundamente e negativamente na arrecadação das receitas fiscais, abalando os sistemas fiscais tradicionais (JOHANNESEN, 2010; JOSEPH, 2004; TANZI, 2000).

Acrescenta-se a isso, o fato dos ordenamentos jurídicos domésticos não estarem coordenados quanto a identificação do sujeito tributável (quem tributar) e do objeto tributável (o que tributar), bem como, a identificação de diferenças mútuas na alocação da base tributável (onde tributar) acaba desencadeando, nas relações transfronteiriças, em lacunas e sobrepo- 
sições, que refletem em situações de dupla tributação e outras de não tributação econômica, por exemplo descasamentos de entidades híbridas, de rendimentos híbridos e de alocação da base tributária ou jurídica, no caso de aplicações díspares dos princípios tributários internacionais de nacionalidade, residência ou fonte (DE WILDE, 2015).

Outro desafio atual está na efetiva tributação da economia digital, já que a renda oriunda dessa forma de se fazer negócios ainda não é satisfatoriamente tributada, o que afronta os princípios da capacidade de pagamento ${ }^{4}$ e o princípio da neutralidade, com consequente violação da estabilidade dos sistemas tributários (PIRES, 2017).

Todo o panorama narrado, tem resultado em Estados como atores cada vez mais estratégicos, já que diante da dificuldade de exercer sua soberania tributária, passaram a competirem entre si com o objetivo de atrair investimento. Essa competição fiscal pode se dar de diversas formas, estando entre as principais medidas: (i) adoção de modelo de tributação territorial, com limitação aos lucros obtidos dentro do Estado de residência e exclusão dos lucros obtidos no exterior; (ii) isenção pelos Estados da fonte dos rendimentos oriundos dos serviços desmaterializados, tal como serviços financeiros e decorrente da economia digital; (iii) não tributação ou tributação significativamente mais baixa, visando atrair registro de patentes (DOURADO, 2019a). Verifica-se a partir da década de 60 a propagação de pequenos territórios com políticas de sigilo bancário e total falta de clareza quanto à identificação dos contribuintes e ausência de tributação (DOURADO, 2019a).

Desta forma, o desafio instituído a partir da realidade econômica e política global consiste na definição do âmbito e escopo da política pública (ADAM; KAMMAS; LAGOU, 2013; HAUPT; PETERS, 2005; SCHÖN, 2000). Isso porque as nações podem oferecer diferentes cestas de políticas, programas, projetos e ações públicas, de âmbitos fiscais, sociais e econômicos, as quais estão interligadas e mutuamente influenciáveis. Trata-se de uma rede de respostas mitigadoras que são implementadas para garantir a soberania e a capacidade de produzir a cidadania e o bem-estar social da população local, mas que acabam ocasionando espaços, lacunas e diferenças das legislações nacionais que podem ser aproveitadas pelo contribuinte em detrimento dos Estado tributante.

Portanto, a globalização provocou desajustes e conflitos políticos, econômicos e sociais e tem sido responsável por profundas implicações e alterações nos poderes e regras tributárias nacionais e internacionais, impactando no ordenamento fiscal soberano de cada nação (PIRES, 2017). Contribuintes pessoas físicas e grandes EMNs estão se aproveitando de um "sistema global de taxação transfronteiriça fragmentado e incoerentemente regulado para evadir e/ou elidir impostos" (OBENLAND, 2017, p. 03), dificultando o cumprimento da fair share, quebrando a neutralidade fiscal, aumentando a desigualdade e impedindo a concretização da justiça fiscal.

No contexto da justiça fiscal global, importantes considerações devem ser analisadas, tal qual indicado na sequência. 


\section{APONTAMENTOS SOBRE AS PRINCIPAIS PERSPECTIVAS DA JUSTIÇA FISCAL}

Tradicionalmente, a justiça fiscal tem sido avaliada sob duas perspectivas principais. A primeira busca verificar como o sistema tributário deve ser usado para fornecer igualdade aos indivíduos, por exemplo a igualdade de oportunidades. Esta perspectiva fundamenta-se no escopo da justiça fiscal distributiva, que se refere à substância do sistema tributário e os respetivos impacto da alocação de recursos na dinâmica das interações pessoais. A segunda perspectiva é alicerçada na ótica processual da justiça fiscal, e se refere ao caráter legítimo e democrático das regras que envolvem o processo de tomada de decisão em questões tributárias.

No âmbito deste artigo, chama atenção a segunda perspectiva. Isso porque, em um contexto transfronteiriço, a justiça vista sob a perspectiva processual se preocupa com regras destinadas a permitir que os países façam por exemplo, escolhas fiscais sobre o tamanho do orçamento e o nível de redistribuição doméstica. Assim, a perspectiva processual poderia ser considerada um pré-requisito para se alcançar a justiça fiscal substantiva e distributiva (PIRLOT, 2020).

Para uma visão cosmopolita, a justiça distributiva deve ser global, e aplicada universalmente a todos os serem humanos em todo o mundo. Em contrapartida, os proponentes da justiça política sustentam a dualidade de um regime de justiça, distinguindo firmemente os níveis nacional e global. Contudo, cada vez mais tem prevalecido que a justiça será efetiva se pensada em nível global, isso porque, a competição fiscal na era da globalização mudou drasticamente a capacidade dos Estados de sustentar as condições necessárias para a provisão de justiça. Assim, a capacidade dos Estados (ricos e pobres) de sustentar unilateralmente as condições domésticas necessárias para à promoção da justiça, está sendo prejudicada (DAGAN, 2017).

Neste contexto, salienta-se que "a justiça pode ser utilizada para avaliar diferentes situações, desde o Direito Penal à economia de mercado e à capacidade contributiva" (DOURADO, 2019a, p. 464). Tradicionalmente, o principal instrumento para se assegurar a justiça é a lei, estritamente associada à soberania do Estado. Entretanto, não somente na área fiscal, mas em todos os ramos do direito, é possível verificar há algumas décadas, o crescimento das "influencias recíprocas de diferentes legislações e ordenamentos estaduais, infraestaduais e supraestaduais na procura da melhor solução para determinados problemas comuns que podem designar problemas globais" (DOURADO, 2019a, p. 459), fato este que pode propiciar o enriquecimento da lei nacional, mas ao mesmo tempo, pode contribuir para o enfraquecimento da soberania tributária.

Justamente em razão do cenário de investimento e trabalho globalizado, com maior mobilidade dos agentes e bases de tributação, as Organizações Internacionais - Ols, como OCDE, FMI, Banco Mundial, Nações Unidas; as organizações supranacionais, como a EU; e organizações especializadas como a ATAF (African Tax Administration Forum) tem tratado do conceito de justiça fiscal, acentuando assim o pluralismo jurídico e dando um conteúdo supranacional para questões domésticas e internacionais, tais como transparência tributá- 
ria, cooperação entre administrações tributárias, ações para minimização e combate a evasão e ao planejamento tributário agressivo (DOURADO, 2019a).

Essas organizações têm explorado o conceito de justiça fiscal, principalmente, de uma perspectiva econômica, na medida em que exigem o pagamento da parcela justa ${ }^{5}$ pelas EMNs e estimulam a concorrência justa ${ }^{6}$ entre Estados, além de demonstrarem uma preocupação com a necessidade de aumentar os níveis de arrecadação fiscal para possibilitar a prestação dos serviços públicos, buscando para isso, tornar as administrações tributárias mais eficientes e justas, exemplos no combate à corrupção e ao planejamento tributário agressivo (BURGERS; VALDERRAMA, 2017).

Ocasionalmente, outras perspectivas de justiça, além da econômica são exploradas nas medidas e posicionamentos das Ols. Alguns relatórios dessas organizações refletem uma perspectiva filosófica e política de justiça, tal como quando: (i) o FMI e o Banco Mundial se referem a questões de legitimidade, fundamentando ser injusto que as empresas locais não sejam competitivas e que os países em desenvolvimento devem ter voz no debate sobre a cooperação regional e global; (ii) a UE e a ATAF se referem ao acordos firmados entre contribuinte e Estado, sob uma abordagem filosófica; ou (iii) quando a OCDE menciona que os cidadãos se tornaram mais sensíveis às questões tributárias, o que mostra preocupação com a dimensão política da justiça (BURGERS; VALDERRAMA, 2017).

A dimensão política da justiça é aparente quando OCDE, FMI, Banco Mundial, Nações Unidas expressam preocupações sobre participação dos países em desenvolvimento na discussão do BEPS e cooperação internacional para estabelecer sistemas tributários justos nos quais os cidadãos possam confiar (BURGERS; VALDERRAMA, 2017).

A relevância da contribuição dessas Ols é verificada quando, em resposta à discussão global sobre justiça no contexto do Projeto BEPS, da G20/OCDE, alguns países mudaram sua legislação doméstica. Em 2015, o Reino Unido e a Austrália decidiram incluir um novo imposto com incidência sobre lucros desviados para garantir que as EMNs paguem sua parcela justa de impostos. A abordagem da Austrália e do Reino Unido concentra-se no pagamento de multinacionais da parcela justa, independentemente dessas multinacionais contribuírem de acordo com a lei. Na Austrália, o novo imposto visa impedir que EMNs que vendem bens e serviços a residentes australianos, evitem os impostos australianos por meio da limitação artificial da sua presença tributável na Austrália. No Reino Unido, o principal objetivo do imposto sobre lucros desviados é combater o planejamento tributário agressivo usado por muitas EMNs para transferir lucros da jurisdição do Reino Unido. Portanto, essas legislações nacionais visam impedir o planejamento tributário agressivo para que as EMNs cumpram com a fair share (BURGERS; VALDERRAMA, 2017).

Referidas iniciativas unilaterais são refutadas pela OCDE, que sustenta que sem uma abordagem global coerente, problemas como os que deram origem ao BEPS provavelmente ressurgirão (BURGERS; VALDERRAMA, 2017).

Desta forma, em um mundo globalizado, tem prevalecido a necessidade do emprego de políticas fiscais adequadas e eficazes para manutenção da soberania tributária nacional e propagação do bem-estar e justiça fiscal, sendo insuficiente que os Estados considerem uni- 
camente seus sistemas jurídicos domésticos para atingir a igualdade e proporcionar justiça, devendo haver cooperação na buscar por soluções globais (DAGAN, 2017).

\section{HARMONIZAÇÃO DAS REGRAS FISCAIS PARA PROMOÇÃO DA JUSTIÇA FISCAL GLOBAL}

Os escândalos tributários retratados na introdução lançaram alguma luz sobre a importância da transparência tributária envolvendo não apenas fraudes fiscais, mas também evasão fiscal e planejamento tributário agressivo (BARANGER, 2017), além de terem intensificado os debates sobre a governança corporativa e fiscal, a cooperação entre administrações tributárias e o cumprimento da fair share ou do ability-to-pay principle como meios de maximizar o bem-estar global e distribuí-lo com justiça, de forma global.

Estudiosos da tributação internacional e os formuladores de políticas ao se envolverem substancialmente nos aspectos práticos da tributação sobre o rendimento no mundo globalizado, ressaltaram a erosão das bases tributárias dos Estados e se empenharam em explorar possíveis soluções, destacando dentre elas, a intensificação da cooperação internacional como tentativa de sustentar as bases tributárias, que por sua vez, possibilita melhor distribuição do bem-estar social (DAGAN, 2017). Contudo, sugere-se que retórica da justiça tributária ainda tem prevalecido em relação a adoção de uma verdadeira agenda substantiva sobre justiça tributária, que implicaria por exemplo, na adoção de políticas fiscais que pudessem oferecer oportunidades econômicas iguais aos cidadãos (PIRLOT, 2020).

Uma série de projetos que incentivam a cooperação, visando o aumento da transparência fiscal e a redução da sonegação fiscal, tem sido objeto da OCDE/G20, desde 2012. Entre as ações apontadas estão: (i) a troca automática de informações sobre renda e ativos transfronteiriços entre autoridades fiscais; (ii) registro público dos verdadeiros beneficiários efetivos de empresas e trustes; (iii) relatório por país de lucros, ativos, vendas, emprego e unidades de negócios corporativos; (iv) regulamentos mais rígidos contra a lavagem de dinheiro; (v) repartir as receitas de impostos corporativos de acordo com a localização das atividades econômicas reais e não das empresas de fachada baseadas em paraísos artificiais; (vi) regulamentação mais rígida das jurisdições bancárias privadas transnacionais, lavagem de dinheiro e sigilo financeiro; e (vii) restringir os incentivos fiscais que investidores individuais e corporativos agora precisam se tornar "cidadãos do nada" para fins fiscais (HENRY, 2016).

Dentre exemplos de experiências bem-sucedidas neste sentido pode-se mencionar o Global Forum on Transparency and Exchange of Information for Tax Purposes ${ }^{7}$ da OCDE que

7 O Fórum Global sobre Transparência e Troca de Informações para Fins Fiscais é um trabalho multilateral sobre transparência e troca de informações para fins fiscais é realizado por membros e não-membros da OCDE desde 2000, atualmente 161 membros, juntamente com 19 observadores. Desde sua reestruturação em 2009, o Fórum Global tornou-se o principal organismo internacional que trabalha na implementação das normas internacionais sobre transparência tributária. O Fórum Global garante que esses altos padrões de transparência e troca de informações para fins fiscais estejam em vigor em todo o mundo por meio de suas atividades de monitoramento e revisão por pares. O Fórum possui um programa de assistência técnica para seus membros visando garantir os benefícios de maior transparência tributária e cooperação internacional para a comunidade mundial, bem como, garantir que os países em desenvolvimento se beneficiem do novo ambiente transparente de impostos. Para maiores informações acessar: https://www.oecd.org/tax/transparency/about-the-global-forum/ 
visa o combate aos paraísos fiscais e a concorrência prejudicial. Por outro lado, tentativas de implementação de hard law supranacionais não são garantia de uma abordagem comum dos Estados-Membros como pode ser verificado na iniciativa da Caribbean Community and Common Market - CARICOM² (BURGERS, 2017; VAN HORZEN, 2017).

O sucesso desses projetos, que visam reduzir a evasão fiscal, aumentando a arrecadação das receitas tributárias com a transferência de riqueza de países mais ricos para os mais pobres permitindo com isso maximizar o bem-estar global e a distribuição deste com justiça, depende da maior cooperação entre os Estados. Contudo, a natureza descentralizada predominante da tributação internacional cria sérios entreves para tanto. Sendo assim é necessário que as nações se conscientizem quanto a necessidade da preservação das bases tributárias e trabalhem juntos para inibir a concorrência fiscal, a evasão fiscal e planejamentos fiscais agressivos, a corrupção local e cartéis governamentais.

Desta forma, o combate eficaz à essas práticas que minam as receitas fiscais dos Estados e impactam na prestação dos serviços sociais necessários para redução da desigualdade deve ser conjunto, por meio de medidas como ampla cooperação internacional e troca global de informações pode reforçar a concorrência eficiente (DAGAN, 2017).

No mesmo sentido acredita-se, também, que o conceito de tax fair competition deve ser melhor empregado e juntamente com o conceito crescentemente utilizado da fair share na tributação (PIRES, 2018). Em um discurso em 2016, o Comissário da EU Vestager explicou "por que a tributação justa é importante", afirmando o seguinte:

Para mim, essa questão da justiça é a mensagem mais importante da aplicação das regras em matéria de auxílios estatais na forma fiscal e sendo meu dever, como Comissário da Concorrência, garantir que as regras sejam aplicadas de maneira justa a qualquer empresa que faça negócios no setor. (...) Os contribuintes não precisam pagar a conta deixada pelas empresas que evitam impostos. E o público deve confiar que há igualdade e justiça para todos, e não apenas para algumas empresas bem conectadas (VESTAGER, 2016, s.p).

A concorrência fiscal justa significa que um país terceiro não deve aplicar medidas fiscais prejudiciais na área da tributação das empresas (DOURADO, 2019b). Sendo assim, imprescindível a distinção de práticas fiscais justas e prejudiciais, apesar da ausência de consenso sobre o que é uma 'taxa de imposto efetiva baixa' ou 'um nível efetivo de tributação significativamente mais baixo, incluindo tributação zero, do que os níveis que geralmente se aplicam no país terceiro'.

O conceito da fair tax competition, que conta com a exigência de um nível mínimo de tributação em países terceiros foi incluído no Pacote Antielisão da UE (COMISSÃO EUROPEIA, 2016) e faz parte da estratégia externa, com países terceiros, da UE sobre boa governança tributária. Ademais, a nível UE, o Código de Conduta no domínio da fiscalidade das empresas (1997) representa um compromisso político dos Estados-Membros que visa combater a concorrência fiscal prejudicial.

8 Os Estados-Membros da CARICOM firmaram em 1 de junho de 1973 acordo para harmonização dos incentivos fiscais para a indústria. Essa iniciativa, ao contrário do que se esperava quando da assinatura, não resultou em na pacificação da abordagem sobre incentivos fiscais pelos Estados-Membros. 
Assim, uma melhor coordenação dos Estados, a partir de harmonização das regras fiscais que visam inibir comportamentos nocivos para a maximização do bem-estar e justiça global, colaboraria ainda para uma governança global.

A governança global proposta pelas Ols cobre questões semelhantes: (i) preocupação e medidas para evitar concorrência prejudicial, sonegação e evasão fiscal e incentivos fiscais desnecessários; (ii) o mapeamento dos incentivos fiscais previstos; (iii) o mapeamento de vantagens e desvantagens de esquemas baseados em volume versus incrementais, bem como de esquemas direcionados; (iv) trabalhar na medição de custos e benefícios de incentivos fiscais e a eficácia de incentivos fiscais; (v) assessoria aos governos na avaliação do sucesso e / ou fracasso dos esquemas de incentivos fiscais; e (vi) assessoria aos governos na obtenção de transparência jurídica, econômica e administrativa (VAN HORZEN, 2017).

Outro exemplo de ação que envolve a harmonização de regras fiscais visando a preservação das receitas tributárias, trata-se da regra global anti-erosiva, intitulada GloBE, esboçada no primeiro semestre de 2019, no OECD/G20 Inclusive Framework (IF) do Projeto BEPS. A proposta consiste em um imposto mínimo global, que serviria como uma solução potencial de consenso global para os desafios da digitalização e os desafios remanescentes de Erosão da Base Tributária e à Transferência de Lucros (BEPS) relacionados à economia dos digitais. A solução de consenso global poderia, compreensivelmente, compreender um padrão mínimo global de tributação dos rendimentos transfronteiriços e uma recomendação de melhores práticas, foi adotada apenas por um subconjunto de jurisdições do IF. Considera-se que o apoio expresso dos Ministros das Finanças do G7 ao imposto mínimo possa ser considerado um fator determinante para aumentar a adesão ao projeto GloBE, contudo resta saber se os países restantes que compõem o G20, bem como os outros membros do Fl, irão, de fato, aderir a essa proposta audaciosa (HO; TURLEY, 2019).

Todas as medidas mencionadas, como a propagação da governança global, adoção de estratégias para observância da fair share e da tax fair competition poderiam levar a uma maior coordenação dos sistemas fiscais nacionais que, a longo prazo, poderia resultar em harmonização, não só em patamar regional, mas em termos globais das questões de governança, como transparência jurídica, econômica e administrativa, voluntariamente ou através de hard law. 0 papel de liderança do G20 nas ONU pode, a longo prazo, resultar em um consenso convincente em relação às normas formuladas, debatidas e implementadas por institutos internacionais, supranacionais e intergovernamentais (VAN HORZEN, 2017).

Uma opção mais extrema seria exigir, em nome da justiça fiscal global, a adoção de recomendação de melhores práticas fiscal em nível multilateral, por meio de uma convenção multilateral adotada em larga escala. Para alguns, os esforços cooperativos e a interdependência dos Estados em um regime multilateral seriam suficientes para dar origem a um dever supranacional de justiça.

Entretanto, os defensores da justiça política estrita afirmam que isso não é suficiente para justificar tal dever de justiça, pois apenas a instituição de um Estado fiscal global ou multilateral (ou algo próximo a ele) possibilitaria tal feito, já que certamente a cooperação multilateral que estabelecesse um Estado global ou Federação de Estados teria que aderir aos princípios de justiça no tratamento de seus constituintes, a fim de adquirir legitimidade. Tal regime poderia, de fato, ser a melhor resposta às preocupações de justiça de cosmopolitas e estatísticos; no entanto, não é apenas uma solução inviável, mas provavelmente 
também uma solução injustificada. Um Estado global provavelmente não responderia particularmente às preferências de seus constituintes, sofreria uma concentração excessiva de poder e falta de prestação de contas, além de ter um sério problema de eficiência (DAGAN, 2017).

Assim, surge como alternativa para o regime multilateral, a criação de uma agência antitruste multilateral que trabalharia para dissolver cartéis de estados que estão expulsando concorrentes, impedindo-os de aumentar os lucros do cartel dos Estados à custa de atores menos poderosos e reduzindo o desperdício do governo. Esse regime potencialmente aumentaria a promoção de bem-estar global, diminuindo os custos de transação, o uso indevido e outras falhas do mercado, além de distribuir mais justamente as receitas. Embora esse tipo de cooperação também se depare com desafios estratégicos, um desenho cuidadoso da governança desses mecanismos cooperativos poderia ajudar a garantir esse regime mais modesto, porém mais distributivo e justo (DAGAN, 2017).

Resumidamente, a verdade é uma só: as nações devem assumir que a justiça fiscal global precisa prevalecer sobre a rivalidade econômica. Portanto, a conscientização dos Estados e de seus contribuintes, a cooperação ampla regional, que deve ser combinada com o diálogo aberto com países terceiros promovidos pelas Ols, apoiadas por organizações supranacionais e intergovernamentais e o estímulo a boas práticas de concorrência fiscal e de cumprimento da fair shair e as iniciativas de governança é o caminho a ser seguido (BURGERS, 2017).

\section{CONSIDERAÇÓES FINAIS}

O cenário atual clama pela cooperação internacional em questões tributárias globais a fim de diminuir ou até mesmo acabar com paraísos fiscais e regimes preferenciais que apenas visam atrair investimento estrangeiro, atingindo, em demasiado, a neutralidade do elemento fiscal. Atualmente, não somente as EMNs, mas também pessoas físicas se aproveitam da facilitada mobilidade das bases de tributação e utilizam a fragmentação e diferenças entre os sistemas fiscais nacionais para evadir e/ou elidir impostos. 0 impactado negativo dessas práticas evasivas é suportado por Estados em todo globo, já que as somas não tributadas atingem cifras de centenas de bilhões dólares todos os anos.

As Ols foram pioneiras na luta contra a evasão, introduzindo medidas para conter as perdas decorrentes da erosão da base tributária e transferências de lucros para paraísos fiscais e regimes preferenciais prejudiciais. Iniciativas como o BEPS - Base Erosion and Profit Shifting - da ONU/OCDE e a criação de uma Plataforma de Colaboração Tributária entre as instituições de Bretton Woods, a OCDE e a ONU foram largamente aceitas pelas nações, que reconhecem os efeitos nefastos da concorrência fiscal prejudicial e dos planejamentos fiscais prejudiciais. Embora há consenso que essas práticas prejudiciais dificultem a sustentabilidade fiscal internacional, questões diversas, como a soberania nacional, impedem que seja alcançado um nível mínimo para tributação direta ou uma harmonização completa dos tributos transfronteiriços. 
Assim, sem haver uma harmonização total da tributação, a nível internacional, cabe precipuamente aos Estados a conscientização quanto a necessidade de enfrentar as deficiências persistentes para governança tributária global, a fim de conjuntamente, poderem implementar por meio de soft ou hard law internacional, medidas mais avançadas e melhor desenvolvidas, como por exemplo, uma convenção multilateral com ampla ratificação e completa adoção pelas nações, que vise garantir o cumprimento da fair share, da fair tax competition ou a criação de uma agência antitruste com atuação global, a fim de possibilitar uma distribuição de riqueza mais igualitária, atingindo com isso, a justiça fiscal global.

A partir dessa cooperação internacional viabilizada pelos Estados, deve-se fomentar uma mudança de mentalidade sobre a elaboração, aprimoramento e cumprimento das regras tributárias na sociedade em geral. Vale ressaltar que a legislação por si só não é suficiente, por esse motivo, tão necessária se faz a conscientização e interesse dos Estados em adotarem iniciativas de cooperação e governança internacional, visando a implementação das ferramentas necessárias de amplificação da governança fiscal global.

Por fim, é de extrema importância que todas as abordagens sobre justiça sejam levadas em consideração no design de um sistema tributário global sustentável, cabendo assim, a ampliação do campo de investigação sobre as percepções globais de justiça e a formulação de uma agenda, que conte com a com a ampla participação pelos Estados, Ols e sociedade civil, para discutir a justiça fiscal em patamar global.

\section{REFERÊNCIAS}

ADAM, Antonis; KAMMAS, Pantelis; LAGOU, Athina. The effect of globalization on capital taxation: What have we learned after 20years of empirical studies? Journal of Macroeconomics, Amsterdam: Elsevier, v. 35, n. 1, p. 199-209, 2013.

BARANGER, Séverine. Progress towards tax transparency: an overview. In: RIBEIRO, João Sérgio; ACOSTA, George Rosa (org.). International Taxation: new challenges. Amsterdam: IBFD Publi, 2017. p. 296.

BRASIL. DECRETO No 19.841, DE 22 DE OUTUBRO DE 1945. Promulga a Carta das Nações Unidas, da qual faz parte integrante o anexo Estatuto da Corte Internacional de Justiça, assinada em São Francisco, a 26 de junho de 1945, por ocasião da Conferência de Organização. Diário Oficial da União, Brasília, DF, 1945. Disponível em: http:// www.planalto.gov.br/ccivil_03/decreto/1930-1949/d19841.htm. Acesso em: 1 jul. 2020.

BRASIL. CONSTITUIÇÃO DA REPÚBLICA FEDERATIVA DO BRASIL - 1988. Diário Oficial da União, Brasília, DF, Brasil, 1988. Disponível em: http://www.planalto.gov.br/ccivil_03/constituicao/constituicao.htm. Acesso em: 15 jun. 2020.

BURGERS, Irene. Tax Incentives, Global Tax Fairness and the Development of Tax Law in DEveloped and Developing Countries: A Multi-Way Flow of Concepts? In: WEBER, Dennis (org.). EU Law and the Building of Global Supranational Tax Law: EU BEPS and State Aid. Amsterdam: IBFD Publi, p. 324, 2017.

BURGERS, Irene; VALDERRAMA, Irma Mosquera. Fairness: A Dire International Tax Standard with No Meaning? Intertax, Alphen aan den Rijn: Kluwer Law International, v. 45, n. 12, p. 767-783, 2017.

COMISSÃO EUROPEIA. COM(2016) 24 final. COMUNICAÇÃO DA COMISSÃO AO PARLAMENTO EUROPEU E AO CONSELHO sobre uma estratégia externa para uma tributação efetiva, 2016. Disponível em: https://eur-lex. europa.eu/legal-content/PT/TXT/HTML/?uri=CELEX:52016DC0024\&from=EN. Acesso em: 15 jun. 2020. 
CONSELHO EUROPEU. RESOLUÇÃO DO CONSELHO E DOS REPRESENTANTES DOS GOVERNOS DOS ESTADOS-MEMBROS, REUNIDOS NO CONSELHO de 1 de Dezembro de 1997 relativa a um código de conduta no domínio da fiscalidade das empresas, 1997. Disponível em: https://eur-lex.europa.eu/legal-content/PT/TXT/PDF/?uri=CELE X:41998X0106\&from=PT. Acesso em: 15 jun. 2020

DAGAN, Tsilly. International Tax and Global Justice. Berlim: Walter de Gruyter GmbH, v. 18, 2017.

DE WILDE, Maarten Floris. Sharing the Piee; Taxing Multinationals in a Global Market. SSRN Electronic Journal, Amsterdam: Elsevier, v. 43, n. 6, p. 438-446, 2015.

DOURADO, Ana Paula. Justiça tributária internacional. Revista Direito Tributário Atual, São Paulo: Instituto Brasileiro de Direito Tributário, v. 41, p. 457-487, 2019a.

DOURADO, Ana Paula. The Priorities for EU Tax Policy. Intertax, Alphen aan den Rijn: Kluwer Law International, v. 47, n. 10, p. $808-810,2019 b$.

FINNERTY, Chis; MERKS, Paulus; PETRICCIONE, Mario;; RUSSO, Raffaele. Fundamentals of International Tax Planning. Amsterdam: IBFD Publi, 2007.

GRINBERG, Itai. Bilding Institutions for a Globalized World - Automatic Information Exchange. In: POGGE, Tomas; MEHTA, Krishen (org.). Global Tax Fairness. Oxford: OXFORD University Press, p. 14-30, 2016.

HAUPT, Alexander; PETERS, Wolfgang. Restricting preferential tax regimes to avoid harmful tax competition. Regional Science and Urban Economics, Amsterdam: Elsevier, v. 35, n. 5, p. 493-507, 2005.

HENRY, James S. Let's Tax Anonymous Wealth. In: POGGE, Tomas; MEHTA, Krishen (org.). Global Tax Fairness. Oxford: OXFORD University Press, 2016.

HO, Khoon Ming; TURLEY, Conrad. Globe - overriding the value creation principle as alodestone of international tax rules? Intertax, Alphen aan den Rijn: Kluwer Law International, v. 47, n. 12, p. 1070-1076, 2019.

ICIJ. Who Uses the Offshore World. Washington/DC, 2013. Disponível em: https://www.icij.org/investigations/ offshore/who-uses-offshore-world/. Acesso em: 10 jun. 2020.

ICIJ. About This Project: Luxembourg Leaks. Washington/DC, 2014. Disponível em: https://www.icij.org/investigations/luxembourg-leaks/. Acesso em: 10 jun. 2020.

ICIJ. About This Project: Swiss Leaks. Washington/DC, 2015. Disponível em: https://www.icij.org/investigations/ swiss-leaks/about-project-swiss-leaks/. Acesso em: 10 jun. 2020.

ICIJ. The Panama Papers: Exposing the Rogue Offshore Finance Industry: About the investigation. Washington/ DC, 2016. Disponível em: https://www.icij.org/investigations/panama-papers/about-the-investigation/. Acesso em: 10 jun. 2020.

JOHANNESEN, Niels. Imperfect tax competition for profits, asymmetric equilibrium and beneficial tax havens. Journal of International Economics, Amsterdam: Elsevier, v. 81, n. 2, p. 253-264, 2010.

JOSEPH, Ghislain T. J. Electronic Commerce and the United Nations Model Double Taxation Convention. Intertax, Alphen aan den Rijn: Kluwer Law International , v. 32, n. 8, p. 387-401, 2004.

OBENLAND,Wolfgang. Opções para fortalecer a governança tributária global. FES, Fried ed. São Paulo: FES, Fried, 2017.

PASSOS, Fernando; BERALDO, Mariana. Fair Share Starbucks. In: SALEME, Edson Ricardo; TYBUSCH, Jerônimo Siqueira (org.). Desenvolvimento econômico sustentável, globalização e transformações na ordem social e econômica II organização CONPEDI/2020. CONPEDI ed. Florianópolis. p. 155-171, 2020.

PIRES, Rita Calçada. Uncoverinh a brave new world on taxation: income from the digital economy. In: RIBEIRO, José Sérgio; ACOSTA, George Rosa (org.). International Taxation: new challenges. Amsterdam: IBFD Publi, p. 296, 2017.

PIRES, Rita Calçada. Manual de Dirieto Internacional Fiscal. Coimbra: Almendina, 2018.

PIRLOT, Alice. The vagueness of tax fairness: A discursive analysis of the commission's 'fair tax agenda'. Intertax, Alphen aan den Rijn: Kluwer Law International, v. 48, n. 4, p. 402-415, 2020. 
SCHÖN, Wolfgang. Tax competition in Europe - the legal perspective. EC Tax Review, Alphen aan den Rijn: Kluwer Law International, v. 9, n. 2, p. 89-104, 2000.

TANZI, Vito. Is there a need for a world tax organization?. The economics of globalization: policy perspectives from public economics. [esssays based on lectures delivered at the 1996 Congress of the International Institute of Public Finance]. Cambridge [u.a.]: Cambridge Univ. Press, p. 173-186, 1999.

TANZI, Vito. Globalization, Technological Developments, and the Work of Fiscal Termites. IMF Working Papers, 2000.

VAN HORZEN, Fred. Go Tell It on the Mountain: Enhanced Transparency: Impact on Relations between Tax Authorities and Taxpayers? In: WEBER, Dennis (org.). EU Law and the Building of Global Supranational Tax Law: EU BEPS and State Aid. Amsterdam: IBFD Publi, 2017.

VESTAGER, M. Why Fair Taxation Matters. In: Discurso proferido na Copenhagen Business School, 9 de setembro de 2016. Copenhagen, 2016. Disponivel em: https://ec.europa.eu/competition/state_aid/newsletter/15092016. pdf. Acesso em: 10 mar. 2020.

ZAKRZEWSKI, Anna; CARRUBBA, Joseph; FRANKLE, Dean; HARDIE, Andrew; KAHLICH, Michael; KESSLER, Daniel; MENDE, Martin; TANG, Tjun; XAVIER, Andre. The Future of Wealth Management - A CEO Agenda. Boston, 2020. Disponível em:https://image-src.bcg.com/Images/BCG-Global-Wealth-2020-Jun-2020_tcm9-251066.pdf. Acesso em: 15 jun. 2020.

Recebido/Received: 21.07.2020.

Aprovado/Approved: 26.09.2020. 